\title{
The Link between Types of Attachment and Childhood Trauma
}

\author{
Atilgan Erozkan \\ Faculty of Education, Mugla Sitk1 Kocman University, Turkey
}

Copyright $(2016$ by authors, all rights reserved. Authors agree that this article remains permanently open access under the terms of the Creative Commons Attribution License 4.0 International License

\begin{abstract}
The study investigated the relationship between childhood trauma and types of attachment and the predictive role of childhood trauma on types of attachment. The sample was composed of 911 (492 female; 419 male) university students at Mugla Sitki Kocman University, in Turkey. Data were collected using the brief screening version of the Childhood Trauma Questionnaire and Relationship Scales Questionnaire. Pearson product-moment correlation analysis was employed to search for relationship between childhood trauma and types of attachment; structural equation modeling was also used for explaining the predictive role of childhood trauma on types of attachment. It was found that the physical, emotional, and sexual abuse, and physical and emotional neglect subdimensions of childhood trauma were positively related to fearful, preoccupied, and dismissing attachment styles; whereas these same variables were negatively related to the secure attachment style. Results were discussed in the light of previous findings and in the context of childhood trauma and attachment styles. Further replications using larger samples should be conducted to explore the relationship between childhood trauma and attachment styles.
\end{abstract}

Keywords Childhood Trauma, Attachment Styles, University Students

\section{Introduction}

With regards to establishing healthy relationships with others such as peers, partners, and their own children in later life, early attachment with caregivers plays a vital role [1]. Secure and healthy relationships between caregivers and children are likely to provide protection from negative effects of trauma experienced in childhood. A secure parental attachment has been shown to help children effectively regulate emotional arousal [2]. Sroufe, Egeland, and Carlson [3] list the possible positive effects of healthy early attachment with caretakers in later life as the capacity of emotional connectedness, the ability to build safe and secure relationships, and the establishment of positive self-esteem. Crusto, Whitson, Walling, Feinn, Friedman, Reynolds, Amer and Kaufman [4] found that caretaker support and healthy parent-child relationships reduce the risk of psychological problems in children after a trauma. According to Howe [5] children who are subject to abuse are usually unable to find their caretaker available, or have caregivers whose behaviours lead to anxiety, fear, and anger.

Historically, caregivers' negligent, unpredictable, or unsafe behaviours may cause trauma in children and minimize the potential of the child with regards to dealing with their longer-term traumatising effects, wherein the child lacks a convenient secure base to turn to for safety when under threat. Hence, along with developing strategic solutions related to pronounced failures in caregiving, finding ways of coping with traumatic experiences appears to be another necessity [6]. Children who have been subject to trauma have certain imperfections in terms of developmental domains, particularly in the sense of social and emotional development [7] such as difficulty or inability to make and sustain friendships; being distant from or exhibiting oppositional behaviour towards parents, caregivers, and authorities and difficulties in developing trust, intimacy, and affection. These children are also likely to lack certain emotions such as empathy, compassion, and remorse; and have a tendency of abusing substances and imitating the same maltreatment and attachment disorder towards their own children when they become adults [8].

Children are particularly susceptible to exposure to traumatic events during early childhood as a critical period [9]. As a consequence of the traumatic events they have been subjected to, children generally experience instabilities with regards to domains which constitute the emotional bases for development such as not trusting in caregivers, losing the expectation of being protected by other people, losing the trust in social agencies, losing confidence towards social justice or retribution and possessing feelings that they will inevitably be victims in the future [10]. Due to trauma, most children will experience educational consequences, namely attention-related and learning disabilities, which would lead to further complications in the child's profile [11]. In 
addition, anxiety disorders, behavior disorders, and substance abuse have all been linked to traumatic events experienced during early childhood [12]. As assessed through measures of neglect and abuse, childhood trauma may negatively affect the functioning of individuals in their adult lives, which may be observed through the relationships established by these individuals with their families, friends, and particularly partners $[13,14]$. The types and frequencies of traumatic experiences (physical, emotional, sexual abuse, and physical and emotional neglect) and whether they were directly or indirectly experienced also can have various negative effects on physical and mental health in adulthood [15].

Primary causes of early childhood vulnerability to trauma include early loss or lack of consistent caregivers; emotional, physical or sexual abuse and various forms of neglect. Children with attachment disorder tend to establish intimate and sometimes overly devout or promiscuous relations with new adults and constantly push away their primary caregiver [7]. Interpersonal childhood traumas (including physical abuse, emotional abuse, sexual abuse, physical neglect, and emotional neglect) have been empirically related to various symptoms observed in adults -which have no somatic explanation- such as chronic pain, headache, and attachment problems [16].

Attachment based relationships are established in the early months and become gradually more complex and sophisticated while developing towards adult maturity. The aforementioned relationships are developed based on the child's requirement of to be protected from danger and the need for comfort under conditions of distress. Children depend on the type of response given by the caregivers to these requirements [16]. The attachment behavioral system presents children a clear survival advantage by maintaining a balance between exploratory behavior and proximity-seeking behavior. Attachment needs remain significant during the lifespan and attachment behavioral system is held to designate human beings from the cradle to the grave [17, 18], cited in [19]. Bowlby suggests that children develop mental models of themselves and of relationships that impact their future relationships [20]. Therefore, Bowlby's attachment theory is the most elaborate model of the psychological mediators, according to later interpersonal functioning [18, 21, 22] cited in [23].

Bartholomew and Horowitz [24] developed a classification system involving one secure and three insecure types -dismissing, preoccupied, and fearful- of adult attachment; those with a secure attachment type generally received a reliable caregiving in their childhood, had a positive view of self and others and did not encounter any problems in depending on other people. On the other hand, people with dismissing type of attachment tend to have received unresponsive caregiving; leading to consider themselves as self-sufficient due to not being able to rely on other people. Individuals with a preoccupied attachment type, report having had caregivers who did not respond to their requirements in a consistent manner. This inconsistency steers individuals to consider themselves as unlovable and urges them to believe that other people are capable to provide support, whereas they do not always intend to. Since preoccupied individuals are never sure whether or not they would get what they need, they either become attentive or "clingy" when it comes to getting support from other people. However, individuals with a fearful type of attachment tend to have had rejecting experiences with caregivers which leading to images of both self and others. Adults with fearful type of attachment have desire for intimacy whereas they are afraid to be rejected. Hence, they tend to alternate between approaching to and avoiding other people in order to get close to them[25].

Individuals having received unpredictable caregiving during their childhood tend to use an ambiguous or preoccupied strategy. As adults, the inconsistent caregiving they experienced makes it hard for them to anticipate the possible responses of other people concerning their requirements for safety and comfort. Since they have had difficulties in anticipating the caregiving responses during childhood, those who use ambiguous or preoccupied strategy type are unable to depend on cognition to anticipate danger. Rather, they rely on their own affective arousal. As it would have been hard to settle and pacify these kinds of children when distressed, the same counts for their adulthood when their attachment system is alerted [26].

Fonagy [27] emphasized that the most destructive factor in an attachment relationship is trauma. Structuring of the brain will be delayed in terms of the development process in case where the parents fail to help their children cope with their anxieties. Furthermore, in case where children experience frightening events with their parents [28], they are likely to develop representations of them in their mind and develop angry and frightening figures leading to constant pain and bad feelings, instead of developing a safe environment in their mind. They are also constantly alerted with regards to the next response of the carers, or how to help them. Affliction experienced by the babies when their relationships are disrupted affects their development process. Unprocessed trauma disturbs mental functioning and affects the new relationships: children prefer relationships which lead to new traumas [29].

In any case, such behaviours conducted by the caregivers confront the children with a dilemma of how to safely approach or avoid the person they are attached to. Although assumed as a collapse of strategy, disorganized attachment appears to be related to more extreme traumas or neglect which brings together the characteristics of the avoidant and ambiguous strategies. These kinds of attachments are thought to represent the collapse of attachment strategies towards caregivers, where either of the parties is frightened [17].

Crittenden [30] suggested two general forms of unresolved trauma as preoccupying and distressed. These forms have certain variations reflecting an individual's 
strategic response to trauma. It should be noted that these responses reflect the person's efforts of self protection from the past events, when they were unable to receive protective caregiving. There seems to be a correlation between the amount of unresolved trauma and higher and more distorted attachment categories mentioned in the dynamic natural model of attachment, where the level of complexity increases when one moves towards the lower segments of the model. Dismissing trauma has a self-protective function enabling individuals to diverge from the truth with regards to dangerous events occurred in the past, due to which the person does not recognize any bad feelings related to these events. Preoccupying trauma also has a similar self-protective purpose, whereas it represents a different response to the dangerous events encountered in the past. Different from dismissed trauma, preoccupying trauma is generally connected to affective alertness and arousal and distorted cognitive prediction of danger. Since individuals have difficulties in reviewing their points of view regarding the events occurred and usually fail to find more convenient and effective ways of integrating it to their responses and understanding of the current dangers, both of the trauma types mentioned above remain unresolved.

Negative and pathogenic caregiving may result in seriously disturbed attachments both in infants and young children [31]. At the extreme stages of the caregiving spectrum, young children may show very abnormal relational behaviours, namely emotionally withdrawn/inhibited or socially indiscriminate/disinhibited behaviours, as a result of severe maltreatment, neglect or institutional care. Increased risk for less adaptive attachment relationships appears to be another relational effect of trauma [32].

It can be seen that, many researchers have found clear evidence that children who experience traumatic events in early childhood are impacted well beyond their youth. In consideration of the above given literature data and information, negative events experienced by individuals in childhood are thought to be related to the types of attachment. Hence, this study's aim is to examine the relationship between childhood trauma and types of attachment.

\section{Materials and Methods}

\subsection{Model}

A cross-sectional model was used in the current study. In this type of research design, researchers collect data on participants of differing ages or developmental levels, at the same time. Thus data are collected for many participants, at one time interval only [33]. Thus, all participants' ages were varied and data was collected in one try for the current study. The sample determination method is purposive sampling. Purposive sampling starts with a purpose in mind and the sample is thus selected to include people of interest and exclude those who do not suit the purpose [33]. This study is a quantitative and relational study aimed at examining the relationship between childhood maltreatment experiences and types of attachment. The data were collected by Childhood Trauma Questionnaire-Short Form [34] and Relationship Scales Questionnaire (RSQ) [35].

\subsection{Participants}

Data were collected by randomly selecting from each department -Psychological Counseling and Guidance, German Language Teaching, Music Education, Science Education, Mathematics Education, Fine Art Education, and Primary Education- of the Faculty of Education in Mugla Sitk1 Kocman University. Instruments used in the context of this research were applied to 940 students. Prior to analyzing the data, students' responses on the instruments were reviewed. It was determined that 29 prospective teachers had left a significant number of instrument items empty (at least $5 \%$ ) or demonstrated central tendency bias; thus, they were excluded from the data set. The data analyses were conducted on the responses of the remaining 911 students, 492 female (54.0\%) and 419 male (46.0\%). Students were in 19-24 age range and, average age was 21.97 with a standard deviation of $2.86 .22 .4 \%$ of the participants were freshmen, $23.9 \%$ sophomores, $23.3 \%$ juniors, and $30.4 \%$ of them were in their senior year.

\subsection{Instruments}

Childhood Trauma Questionnaire-Short Form (CTQ-SF): CTQ-SF [34] evaluates the childhood maltreatment experiences. It is a retrospective self-report questionnaire composed of 28 items which was conceived to assess with five negative childhood experience types which are physical abuse (e.g., "I believe that I was physically abused"); emotional abuse (e.g. "People in my family called me "stupid, lazy, or ugly"); physical neglect (e.g., "I had to wear dirty clothes"); emotional neglect (e.g., "I felt that someone in my family hated me"); and sexual abuse (e.g., "Someone molested me"). Each of the five negative experience types mentioned above are assessed across the five items, where an additional three items assess the individual's tendencies to minimize or deny their experiences involving abuse. Participants respond the each statement on a 1 to 5 scale from 1 (never true) to 5 (very often true). For types of abuse, the scores may range from 5 to 25 [36], whereas the coefficients of validity, reliability, and test-retest reliability ranged from .79 to .85 in an average period of 4 months. Coefficients of internal consistency reliability ranged from .66 to .92 in both clinical and nonclinical research participants. The Turkish version of the CTQ-SF was adapted by Kaya [37] who set forth the coefficients of internal consistency as $.79, .81, .38, .81$, and .80 , and test-retest reliability coefficient as .78. CTQ-SF's parallel form validity was tested with the Beck Depression Inventory 
[38], State-Trait Anxiety Inventory [39], and Rosenberg Self-Esteem Inventory [40] $\mathrm{r}=.46, \mathrm{r}=.43$, and -.41 . The Cronbach's alpha for the subscales in this study was calculated $.82, .83, .66, .84$, and .80 .

Relationship Scales Questionnaire (RSQ): The RSQ Developed by Griffin and Bartholomew [41] and adapted by Sumer and Gungor [35] for Turkish participants, RSQ was used to identify the students' attachment types. It is a self-report questionnaire and composed of a 30-item Likert scale which enables the measurement of four different types of attachment (secure, fearful, preoccupied, and dismissing). On a seven-point scale, samples are asked to rate their agreement for each item and the extent to which each statement best describes their points of view in intimate relationships. Coefficients of test-retest reliability of the scale ranged from .54 to .78 . The scale's parallel form validity was assessed with the Relationship Questionnaire [24], where the coefficients of correlation ranged from .49 to .61. The Cronbach's alpha for the subscales in this study was found to be .81 for secure attachment, .84 for fearful attachment, .78 for preoccupied attachment, and .79 for dismissing attachment style.

\subsection{Procedures}

A permit for data collection was obtained from the Dean's Office of Faculty of Education in Mugla Sitk1 Kocman University, and the data were gathered in the randomly selected departments and classes by researcher. Data collection procedure was carried out by providing prospective teachers with the appropriate environment and sufficient time for answering the questions in groups in the classroom.

\subsection{Data Analysis}

SPSS 19.00 (Statistic Program for Social Sciences) and the LISREL 8.70 package programs were used for the statistical analyses of the data. In this context, Pearson product-moment correlation analysis and structural equation modelling were used for analysing the connection between childhood traumas and attachment styles. Structural equation modelling (SEM) is a statistical technique which uses the combination of statistical data and qualitative causal presumptions in order to test and estimate causal relations. The data analysis model is tested parallel to the measurement data available in order to find out to what extent the model fits the data. The causal presumptions which form the basis of this model may be verified by means of being tested against the data. Among the strengths of SEM, one of the most significant one is its capability to generate latent variables, which may not be directly measured but rather figured out from the previously measured variables, serving to reach the latent variables. This application ensures various benefits to the modeller such as the ability to observe the unreliability of measurement and the structural connections between the latent variables which must be considered exactly. Factor analysis, path analysis, and regression analysis display special cases of SEM [42-44]. In this study, the model was constructed by means of testing the relationships between the variables of childhood maltreatment experiences and attachment styles, using SEM.

\section{Results}

According to the results of this research there is a significant relationship between negative childhood experiences and attachment styles, and subdimensions of childhood trauma important predictors of attachment styles for prospective teachers.

\subsection{The Relationship between Subdimensions of Childhood Trauma and Attachment Styles}

The relationship between subdimensions of childhood trauma and attachment styles was tested by using Pearson correlation analysis and results are presented in Table 1.

Table 1 shows that there is a negative and significant relationship between physical abuse, emotional abuse, physical neglect, emotional neglect, and sexual abuse subdimensions of childhood trauma and the secure attachment style but there is a positive and significant relationship with the fearful, preoccupied, and dismissing attachment styles.

Table 1. The Correlations between Attachment Styles and Subdimensions of Childhood Trauma

\begin{tabular}{|c|c|c|c|c|c|}
\hline & Physical abuse & Emotional abuse & Physical neglect & Emotional neglect & Sexual abuse \\
\hline Secure attachment & $-.48^{* *}$ & $-.52^{* *}$ & $-.40^{* *}$ & $-.57^{* *}$ & $-.37^{* *}$ \\
\hline $\begin{array}{c}\text { Fearful attachment } \\
\text { Preoccupied } \\
\text { attachment }\end{array}$ & $.45^{* *}$ & $.50^{* *}$ & $.41^{* *}$ & $.51^{* *}$ & $.44^{* *}$ \\
\hline Dismissing attachment & $.39^{* *}$ & $.43^{* *}$ & $.34^{* *}$ & $.42^{* *}$ & $.45^{* *}$ \\
\hline
\end{tabular}

$* \mathrm{p}<.01$ 


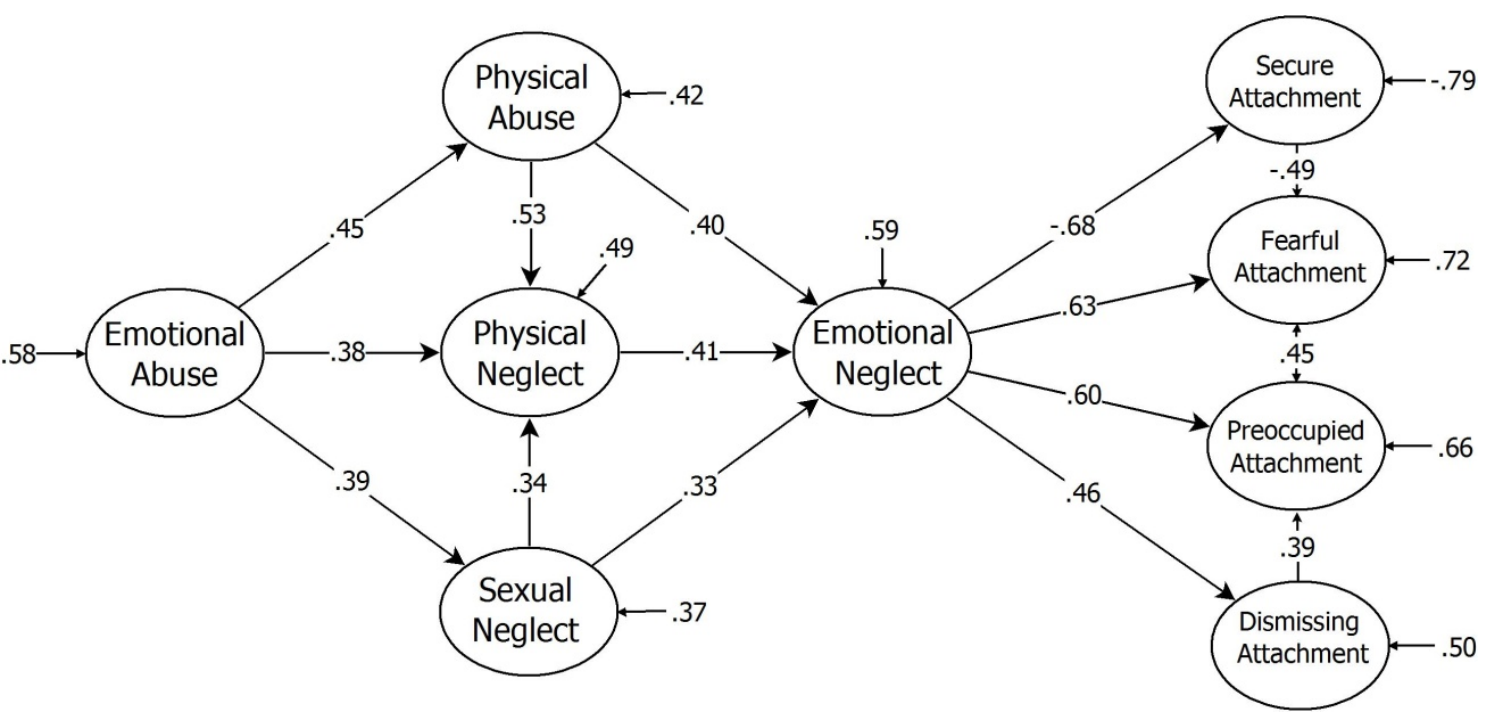

Figure 1. Path Diagram of Significant Predictors of Attachment Styles (Developed Structural Model)

\subsection{The Prediction of Attachment Styles by Subdimensions of Childhood Trauma}

Structural equation modeling was performed to predict attachment styles by subdimensions of childhood trauma and the results are given in Figure 1. Figure illustrates the developed structural model (standardized coefficients).

According to the data obtained the total points of subdimensions of childhood trauma predict the attachment styles between .33 and .79. Figure 1 shows whether the variables are consistent or not is analyzed. As can be seen in Figure 1, the data obtained fit well model. The fitness coefficients related to the developed structural -final- model are above the acceptable limits. For example, the value of $\chi 2: 877.23$, df: 389, NFI.97, NNFI.98, IFI.97, CFI.97, GFI.96, AGFI.94, RMR.05, SRMR.04, RMSEA.04, and $\chi 2 / \mathrm{df}$ is 2.25 . These values indicate that the model is acceptable [43]. Standardized path coefficients were used to explain the effect of the independent variables -subdimensions of childhood trauma- on attachment styles. Path coefficients ranged from .33 and .79 . According to [43], path coefficients with absolute values less than .10 could indicate a "small effect", values around .30 could suggest a "typical effect" or "medium effect", and a "large effect" could be indicated by coefficients with absolute values $\geqslant .50$. In the current study, all of these values were $>.30$.

\section{Discussion}

Results indicated that there was a significant negative relationship between physical abuse, emotional abuse, physical neglect, emotional neglect, and sexual abuse subdimensions of childhood trauma and secure attachment style. Results also indicated that there were significant positive relationships between physical abuse, emotional abuse, physical neglect, emotional neglect, and sexual abuse subdimensions of childhood trauma and insecure types of attachment (fearful, preoccupied, and dismissing attachment styles). These results indicated that participants displaying relatively high levels of physical abuse, emotional abuse, physical neglect, emotional neglect, and sexual abuse subdimensions of childhood trauma tended to report insecure types of attachment (fearful, preoccupied, and dismissing attachment styles).

The relationship between childhood trauma and insecure types of attachment (fearful, preoccupied, and dismissing attachment styles) has been supported empirically. For instance, Stalker and Davies [45] observed that a high percentage of survivors from childhood sexual abuse had a preoccupied and insecure type of attachment. As for larger scale samples, Alexander [46] and Styron and Janoff-Bulman [16] revealed the association between the events of sexual abuse in the past and insecure type of attachment presented by adults. Prior studies which set forth empirical connections between childhood trauma and attachment seem to be consistent with the hypothesis that the insecure attachment accommodates the relation between childhood trauma and increased somatic symptom observed in adults. This hypothesis suggests that childhood trauma provokes the development of insecure attachment which involves the expectation that other people will not meet the individual's emotional requirements.

Since Bowlby's detailed studies in 1950s and 1960s, transmission of types of attachment from parent to child has been a widely discussed research area in childhood psychology. Studies conducted on identical twins showed that no matter adoptive or biological, it was the mother's type of attachment throughout the individual's childhood which was the key factor regarding the child's attachment style, rather than genetics. Other studies have revealed that insecure types of attachment may be partly the result of the poor relationship between the child's caregiver and his/her partner. These unhealthy relationships are widely observed 
particularly among those who -themselves- have unhealthy attachment styles [6].

In infancy, there appears to be a connection between childhood maltreatment and insecure type of attachment. Infants exposed to maltreatment tend to display an insecure type of attachment [47]. In addition, the previous research has proved the link between emotional abuse in childhood and development of an insecure type of attachment [48]. It was suggested by Riggs and Kaminski [49] that emotional abuse experienced in the childhood was a unique sign of severe attachment anxiety among other forms of child maltreatment and that solely emotional maltreatment posed an additional risk for insecure attachment, although all forms of childhood maltreatment were likely to be significantly associated with insecure adult attachment. Hence, emotional abuse experienced in childhood is a significant sign of insecure attachment in adulthood and would be more enlightening to consider than other forms of abuse widely studied such as sexual or physical abuse.

The self-trauma model presented by Briere [50] shows how trauma interferes with the development of child, particularly his/her attachment system. Attachment system is among the fundamental action systems regulating responses to threats and preventing their interference to the daily action systems. When the attachment system is disrupted, individuals tend to focus more on issues like security and safety and ignore their development in other areas such as exploring, learning and establishing interpersonal relationships (daily action systems) [51]. Due to the aforementioned disruption, adults who were exposed to childhood trauma are likely to develop impaired attachment types with their partners.

While researchers focusing on attachment agreed on the significance of trauma on attachment and vice versa, [52] took it one step further with the concept of "attachment-related traumas". Attachment-related traumas originate from events where "a frightening experience is accompanied by, or results from, the appraisal of loss, rejection, or abandonment by an attachment figure". These may include both the physical or psychological loss of the caregiver or "extreme forms" of separations from caregivers which pose a threat to survival, since the survival of the child is closely related to the presence of and protection provided by the parents. Although not considered as an actual threat to survival, attachment-related traumas in adulthood are detrimental particularly due to the fact that the threat to self is accompanied by the threat of loss or abandonment by an attachment figure.

Kobak, Cassidy and Zir [52] suggest four types of attachment-related traumas. The first type of attachment-related trauma is attachment disruptions, or unanticipated and/or prolonged separations involving very little communication where there is no common plan for reunion. The second one involves the events where the child is sexually abused by the attachment figure, which is particularly detrimental due to generating a dilemma for the child who is both in need of and is afraid from the attachment figure. The third type is the loss of an attachment figure. The fourth one is attachment injuries or "wounds that arise from abandonment by a present attachment figure in a situation of urgent need".

Previous studies suggested that children exposed to sexual abuse and neglect possessed the characteristics of avoidant type of attachment [53], and those who were neglected developed avoidant/ambivalent type of attachment [54]. Studies focused on adults further revealed that individuals exposed to traumas in the childhood developed an avoidant [55] and preoccupied [56] type of attachment and that such children lacked the support of their parents and thus, developed less attachment behaviour [57]. Parent-child relationships and other environmental factors also can have important effect on children's reaction to trauma [58].

Being exposed to abuse of particularly the proximities results in the preoccupied attachment of the individual, where the level of attachment increases in stressful situations due to the fact that the basis of a secure attachment also includes the development of rupture behaviour at any time. It is not possible for a child who was abused and reared in a traumatic atmosphere to develop good rupture behaviour [56]. Children exposed to abusive and neglecting environments are likely to present distressed behaviour which is hard to control and may also consider their environments as unsafe. As a result of their caregivers' unwillingness and/or inability to help them regulate their arousal, these children may lack the ability to organize themselves both physiologically and psychologically and may not process their experience in a harmony [8].

Interpersonal abuse and neglect experienced in the childhood imposes a risk for individuals in terms of attachment insecurity since it significantly disturbs psychological development such as the development of positive internal working models of self and other. From the attachment point of view, it has a conceptual significance when considered that children having been exposed to interpersonal abuse and neglect grow up with more negative self-models and higher attachment anxiety and other negative models such as greater levels of avoidance from attachment [59]. Interpersonal abuse experience in childhood also generates a dilemma in which children rely on an expect nurturance from people by whom they are abused [52]. Furthermore, for the aim of remaining attached to the abusive caregiver, children may be obligated to implement unorganized strategies such as dissociation. [60] and Main and Morgan [61] suggested that traumas experienced in both childhood and adolescence with associated disorganized attachment result in the vulnerability of the individual to dissociative disorders and to dissociative reactions to traumas in his/her later life.

This study has certain limitations. First of all, the focus has been limited to specifying the connection between trauma experienced in the childhood and types of attachment observed in prospective teachers. With this 
regard, it was a retrospective study. Although challenging; future studies are required in order to examine the psychological mechanism which determines the individual's mental representations of self, others, and attachment patterns in intimate and personal relationships (parents, partner) from a longitudinal point of view. Second limitation was that solely self-report measures were used during the data collection. Although participants were asked to be as honest as possible while answering the surveys, it was not possible to verify to what extent they were provided accurate responses to questions, particularly to those which required answers regarding any abuse and neglect they have been exposed to in their childhood. The third limitation is that all the participants were composed of undergraduate students of a mid-sized state university in Mugla, Turkey. With this regard, generalizing the results of this study to samples other than these students would be difficult. In order to cross-validate the results of this study with other samples, future studies are required.

In spite of these limitations, the results of this study make certain contributions to current literature in certain aspects. First of all, within the framework of this study, a connection between traumatic experiences and types of attachments among undergraduates was revealed. Secondly, this research proved that being exposed to early relational trauma could play a vital role in the initiation of attachment problems which can be associated with possible abuse and neglect experienced at early ages and the development of unhealthy relationships. Thirdly, these results set worth certain evidences indicating that traumatic experiences are connected to a significant level of fearful, preoccupied, and dismissing attachment types and that insecure type of attachment poses a risk in the development of post-traumatic emotional difficulties. This suggests the possible significant role of traumatic experiences and reactions on the types of attachment.

\section{Conclusions}

The effects of negative early experiences on the future development of individuals are increasingly considered as having long-term adverse effects on both physiological and mental health. In order to reveal the mechanisms associating traumatic experiences of caregivers to their effects on attachment with children, specific studies are required. Future researches should focus on how attachment relationships facilitate or complicate the child's capability of identifying, integrating and coping with intense emotions and behaviours resulting from exposure to trauma and how these events are related to beliefs and expectations of safety in both ways. Counselors and clinicians may assist adults and children to develop healthier functioning, with better knowledge about the complicated interplay of trauma, cognitions, expectations, emotions, and behaviours. With this regard, future researches are required for finding ways to establish therapeutic connections with people with insecure attachment and the victims of caregivers. Counselors who work with these people can provide preventive psychoeducation about these important issues -insecure attachment and trauma- and initiate referrals to counselors trained to work with early childhood trauma. In this way, young people benefit from psychoeducation aimed at teaching parents/caretakers about child development and parenting styles. Counselors who work with traumatized young people struggle to reduce risk factors and promote protective factors while exploring preventive methods, which may reduce young people's exposure to traumatic life experiences. Further efforts are required to reveal the nature of the aspects of attachment across gender, age, socioeconomic level, and type of trauma.

\section{Acknowledgements}

We are very grateful to experts for their appropriate and constructive suggestions to improve this template.

\section{REFERENCES}

[1] D. Howe, M. Brandon, D. Hinings et al., Attachment theory, child maltreatment, and family support: A practice and assessment model, Mahwah, New York: Lawrence Erlbaum Associates, 1999.

[2] J. E. Aspelmeier, A. N. Elliott, and C. H. Smith, "Childhood sexual abuse, attachment, and trauma symptoms in college females: The moderating role of attachment," Child Abuse \& Neglect, vol. 31, no. 5, pp. 549-566, 2007.

[3] L. A. Sroufe, B. Egeland, and E. A. Carlson, "One social world," Minnesota Symposia on Child Psychology: Vol. 30. Relationships in developmental context W. A. Collins and B. Laursen, eds., Hillsdale, NJ: Erlbaum, 1999.

[4] C. A. Crusto, M. L. Whitson, S. M. Walling et al., "Posttraumatic stress among young urban children exposed to family violence and other potentially traumatic events," Journal of Traumatic Stress, vol. 23, no. 6, pp. 716-724, 2010.

[5] D. Howe, Child abuse and neglect: Attachment, development and intervention, Basingstoke: Palgrave Macmillan, 2005.

[6] C. Purnell, "Childhood trauma and adult attachment," Healthcare Counseling \& Psychotherapy Journal, vol. 10, no. 2, pp. 9-13.

[7] A. Cook, J. Spinazzola, J. Ford et al., "Complex trauma in children and adolescents," Psychiatric annals, vol. 35 , no. 5 , pp. 390-398, 2005.

[8] B. A. Van der Kolk, "Editorial introduction: Child abuse \& victimization," Psychiatric Annals, vol. 35, pp. 374-378, 2005.

[9] A. F. Lieberman, A. Chu, P. Van Horn et al., "Trauma in early childhood: Empirical evidence and clinical implications," Development and Psychopathology, vol. 23, 
no. 2 , pp. 397-410, 2011.

[10] B. E. Saunders, and Z. W. Adams, "Epidemiology of traumatic experiences in childhood," Child and Adolescent Psychiatric Clinics of North America, vol. 23, no. 2, pp. 167-184, 2014.

[11] B. A. Van der Kolk, "Developmental trauma disorder," Psychiatric Annals, vol. 35, no. 5, pp. 401-408, 2005.

[12] K. Kanel, A guide to crisis intervention, Belmont, CA: Cengage Learning, 2014.

[13] P. M. Crittenden, and A. Landini, The adult attachment interview: Assessing psychological and interpersonal strategies, New York: Norton, 2011.

[14] C. L. Kisiel, T. Fehrenbach, E. Torgersen et al., "Constellations of interpersonal trauma and symptoms in child welfare: Implications for a developmental trauma framework," Journal of Family Violence, vol. 29, no. 1, pp. $1-14,2014$.

[15] J. Read, R. Fosse, A. Moskowitz et al., "The traumagenic neurodevelopmental model of psychosis revisited," Neuropsychiatry, vol. 4, no. 1, pp. 65-79, 2014.

[16] T. Styron, and R. Janoff-Bulman, "Childhood attachment and abuse: Long-term effects on adult attachment, depression, and conflict resolution," Child Abuse \& Neglect, vol. 21, no. 10, pp. 1015-1023, 1997.

[17] M. S. Ainsworth, "Attachments beyond infancy," American Psychologist, vol. 44, no. 4, pp. 709-716, 1989.

[18] J. Bowlby, The making and breaking of affectional bonds, New York: Basic Books, 1979.

[19] A. Erozkan, "Assessment of social problem solving with respect to emotional intelligence," The Online Journal of Counselling Education, vol. 2, no. 3, pp. 16-32, 2013.

[20] C. Hazan, and P. R. Shaver, "Attachment as an organizational framework for research on close relationships," Psychological Inquiry, vol. 5, no. 1, pp. 1-22, 1994.

[21] J. Bowlby, Attachment and loss: Vol. 1. Attachment, New York: Basic Books, 1969.

[22] J. Bowlby, "Attachment and loss: Vol. 2. Separation: Anxiety and anger," Basic Public, 1973.

[23] A. Erozkan, "Rejection sensitivity levels with respect to attachment styles, gender, and parenting styles: A study with Turkish students," Social Behavior and Personality: An international journal, vol. 37, no. 1, pp. 1-14, 2009.

[24] K. Bartholomew, and L. M. Horowitz, "Attachment styles among young adults: A test of a four-category model," Journal of Personality and Social Psychology, vol. 61, no. 2, pp. 226-244, 1991.

[25] E. Wood, and S. Riggs, "Adult attachment, cognitive distortions, and views of self, others, and the future among child molesters," Sexual Abuse: A Journal of Research and Treatment, vol. 21, no. 3, pp. 375-390, 2009.

[26] P. M. Crittenden, Raising parents: Attachment, parenting and child safety, Cullompton, Devon: Willan, 2013.

[27] P. Fonagy, Attachment, trauma and psychoanalysis: Where psychoanalysis meets neuroscience, London, UK: Karnac Books, 2010.

[28] D. Thakar, B. Coffino, and A. F. Lieberman, "Maternal symptomatology and parent-child relationship functioning in a diverse sample of young children exposed to trauma," Journal of Traumatic Stress, vol. 26, no. 2, pp. 217-24, Apr, 2013.

[29] Y. H. Roberts, C. A. Campbell, M. Ferguson et al., "The Role of parenting stress in young children's mental health functioning after exposure to family violence," Journal of Traumatic Stress, vol. 26, no. 5, pp. 605-612, 2013.

[30] P. M. Crittenden, "A dynamic-maturational approach to continuity and change in pattern of attachment," The organization of attachment relationships: Maturation, culture, and context, P. M. Crittenden and A. H. Claussen, eds., pp. 358-383, Cambridge: Cambridge University Press., 2000.

[31] M. Rincón-Cortés, and R. M. Sullivan, "Early life trauma and attachment: Immediate and enduring effects on neurobehavioral and stress axis development," Frontiers in Endocrinology, vol. 5, no. 33, pp. 1-15, 2014.

[32] A. S. Breidenstine, L. O. Bailey, C. H. Zeanah et al., "Attachment and trauma in early childhood: A review," Journal of Child \& Adolescent Trauma, vol. 4, no. 4, pp. 274-290, 2011.

[33] J. R. Fraenkel, N. E. Wallen, and H. H. Hyun, How to design and evaluate research in education: McGraw-Hill New York, 1993

[34] D. P. Bernstein, J. A. Stein, M. D. Newcomb et al., "Development and validation of a brief screening version of the Childhood Trauma Questionnaire," Child Abuse \& Neglect, vol. 27, no. 2, pp. 169-190, 2003.

[35] N. Sümer, and D. Güngör, "Psychometric evaluation of adult attachment measures on Turkish samples and a cross-cultural comparison," Turk Psikoloji Dergisi, vol. 14, no. 43, pp. 71-109, 1999.

[36] C. D. Scher, M. B. Stein, G. J. Asmundson et al., "The childhood trauma questionnaire in a community sample: psychometric properties and normative data," Journal of Traumatic Stress, vol. 14, no. 4, pp. 843-857, 2001.

[37] S. Kaya, "The adaptation of the brief screening version of the Childhood Trauma Questionnaire into Turkish," Institute of Education Sciences, Mugla S1tk1 Kocman University, Mugla, Turkey, 2014.

[38] A. T. Beck, Cognitive therapy of depression, New York: Guilford Press, 1979.

[39] C. D. Spielberger, R. L. Gorsuch, R. E. Lushene et al., State-trait anxiety inventory (self-evaluation questionnaire), Palo Alto, CA: Consulting Psychololgists Press, 1970.

[40] M. Rosenberg, Society and the adolescent self-image (rev. ed.), Middletown, CT, England: Wesleyan University Press, 1989.

[41] D. W. Griffin, and K. Bartholomew, "Models of the self and other: Fundamental dimensions underlying measures of adult attachment," Journal of Personality and Social Psychology, vol. 67 , no. 3, pp. 430-445, 1994.

[42] L. G. Grimm, and P. R. Yarnold, Reading and understanding 
more multivariate statistics, Washington, DC: American Psychological Association, 2000.

[43] R. B. Kline, Principles and practice of structural equation modeling, New York: Guilford Publications, 2005.

[44] N. Sümer, "Structural equation modelling: Basic concepts and applications," Turkish Psychological Articles, vol. 3, no. 6, pp. 49-74, 2000

[45] C. A. Stalker, and F. Davies, "Attachment organization and adaptation in sexually-abused women," Canadian Journal of Psychiatry. Revue Canadienne de Psychiatrie, vol. 40, no. 5, pp. 234-240, 1995.

[46] P. C. Alexander, "The differential effects of abuse characteristics and attachment in the prediction of long-term effects of sexual abuse," Journal of Interpersonal Violence, vol. 8, no. 3, pp. 346-362, 1993.

[47] J. C. Baer, and C. D. Martinez, "Child maltreatment and insecure attachment: a meta - analysis," Journal of Reproductive and Infant Psychology, vol. 24, no. 3, pp. 187-197, 2006

[48] S. A. Riggs, "Childhood emotional abuse and the attachment system across the life cycle: What theory and research tell us," Journal of Aggression, Maltreatment \& Trauma, vol. 19, no. 1, pp. 5-51, 2010.

[49] S. A. Riggs, and P. Kaminski, "Childhood emotional abuse, adult attachment, and depression as predictors of relational adjustment and psychological aggression," Journal of Aggression, Maltreatment \& Trauma, vol. 19, no. 1, pp. 75-104, 2010.

[50] J. Briere, "A self-trauma model for treating adult survivors of severe child abuse," The APSAC handbook on child maltreatment, J. Briere, L. Berliner, J. A. Bulkley et al., eds., pp. 140-157, Thousand Oaks, CA,: Sage Publications, Inc, 1996.

[51] K. Lyons-Ruth, "Dissociation and the parent-infant dialogue: A longitudinal perspective from attachment research," Journal of the American Psychoanalytic Association, vol. 51, no. 3, pp. 883-911, 2003.

[52] R. R. Kobak, J. Cassidy, and Y. Zir, "Attachment-related trauma and posttraumatic stres disorder: Implications for adult adaptation," Adult attachment: theory, research, and clinical implications, W. S. Rholes and J. A. Simpson, eds., pp. 388-407, New York: Guilford Press, 2004.

[53] B. Egeland, and L. A. Sroufe, "Attachment and early maltreatment," Child Development, vol. 52, no. 1, pp. 44-52, 1981.

[54] R. Finzi, A. Ram, D. Har-Even et al., "Attachment styles and aggression in physically abused and neglected children," Journal of Youth and Adolescence, vol. 30, no. 6, pp. 769-786, 2001.

[55] L. Gauthier, G. Stollak, L. Messé et al., "Recall of childhood neglect and physical abuse as differential predictors of current psychological functioning," Child Abuse \& Neglect, vol. 20, no. 7, pp. 549-559, 1996.

[56] M. E. Deniz, "The relationships between attachment styles with child abuses and guilt-shame in adolescence," Eurasian Journal of Educational Research, vol. 22, pp. 89-99, 2006.

[57] A. A. Levendosky, A. Huth-Bocks, and M. A. Semel, "Adolescent peer relationships and mental health functioning in families with domestic violence," Journal of Clinical Child and Adolescent Psychology, vol. 31, no. 2, pp. 206-218, 2002

[58] K. E. Buss, J. M. Warren, and E. Horton, "Trauma and treatment in early childhood: A review of the historical and emerging literature for counselors," The Professional Counselor, vol. 5, no. 2, pp. 225-237, 2015.

[59] L. Earls, "The relationship between adult attachment and trauma," Department of Psychology, Eastern Michigan University, USA, 2010.

[60] G. Liotti, "Disorganized/disoriented attachment in the etiology of the dissociative disorders," Dissociation: Progress in the Dissociative Disorders, vol. 5, no. 4, pp. 196-204, 1992.

[61] M. Main, and H. Morgan, "Disorganization and disorientation in infant strange situation behavior," Handbook of dissociation: Theoretical, empirical, and clinical perspectives L. K. Michelson and W. J. Ray, eds., pp. 107-138, New York: Springer, 1996. 